\title{
Chronic pulmonary arterial hypertension in children
}

Authors: A.D. Bruwer and S.C. Brown

A D Bruwer (principal specialist/senior lecturer),

S C Brown (principal specialist/senior lecturer).

Division of Paediatric Cardiology, Paediatrics \& Child Health,

Faculty of Health Sciences, University of the Free State, Bloemfontein

Corresponding author

Dr A D Bruwer

Department of Paediatric Cardiology (G 69),

Faculty of Health Sciences,

University of the Free State

PO Box 339, Bloemfontein, 9300

Email: gnpkadb.md@mail.uovs.ac.za

\section{ABSTRACT Pulmonary arterial hypertension, although not} common in children, has a poor prognosis. The definition, modern classification, causes and pathogenesis are discussed. Although the pathogenesis is complex and not completely understood, we now have a better understanding of it. The mechanisms and structural alterations underlying vasoconstriction of the pulmonary vasculature, remodelling of the pulmonary vessel wall and progressive obstruction and obliteration of the vascular bed with thrombosis are set out with the different mediators involved. Diagnosis can be difficult and a high level of suspicion is necessary to achieve an early diagnosis. The approach to management includes a methodical workup. The medication options discussed are based on an understanding of the pathophysiology.

\section{INTRODUCTION}

Pulmonary arterial hypertension (PAH) in childhood is a progressive and, in most cases, fatal disease of the pulmonary vasculature. Although seen regularly by cardiologists, it is less commonly seen by paediatricians. It affects fewer than two adults per million population, and probably less children. The clinical course can be one of rapid deterioration, with death occurring within three years of diagnosis in adults, and less than one year in children. ${ }^{(1,2)}$

In the last decade, a better understanding of the pathophysiology has led to significant improvements in the treatment options, which now include oral calcium channel blockers, anticoagulation, continuous intravenous prostacyclin infusion, aerosolised prostacyclin, endothelin receptor blockers and more recently a type 5 phosphodiesterase inhibitor, namely sildenafil. (3) As is often the case when managing children, most of our knowledge is based on experience and findings in adults.

\section{DEFINITION}

The definition of pulmonary arterial hypertension in children is the same as that in adults. The normal pulmonary vasculature is a low pressure system with less than one quarter the pressure and one tenth the resistance to flow observed in the systemic vascular bed. Pulmonary hypertension refers to the haemodynamic state in which the pressure measured in the pulmonary artery is elevated. By consensus, pulmonary arterial hypertension is regarded as a mean pulmonary artery pressure greater than $25 \mathrm{~mm} \mathrm{Hg}$ at rest and greater than $30 \mathrm{~mm} \mathrm{Hg}$ with exercise in the setting of normal or reduced cardiac output, with a normal pulmonary artery wedge pressure, namely $15 \mathrm{~mm} \mathrm{Hg}$ or less. (4)

Children may have normal to high pulmonary artery pressure at rest, but have an exaggerated increase in response to exertion, therefore exercise haemodynamics are important for the diagnosis. ${ }^{(5)}$ Unfortunately, this is often not possible in the younger children.

\section{CLASSIFICATION AND CAUSES}

A greater understanding of the disease has led to a rethinking of the diagnostic classification of pulmonary arterial hypertension. The first classification of pulmonary arterial hypertension was after the World Health Organization (WHO) Conference on pulmonary hypertension in 1973. The second was at the 2nd WHO Conference in 1998 in Evian, France and the most recent at the 3rd World Conference in Venice in 2003.

This classification separates pulmonary arterial hypertension from pulmonary venous hypertension, pulmonary hypertension associated with respiratory system abnormalities and hypoxia as well as a range of other less common disorders which can also cause pulmonary arterial hypertension.

The term primary pulmonary hypertension was, until recently, the term used to describe familial disease, or sporadic disease of unknown cause. At the World Pulmonary Arterial Hypertension Symposium in 2003, the term "primary pulmonary hypertension" was set aside and replaced with idiopathic pulmonary arterial hypertension (IPAH). Where a hereditary basis is supported by genetic findings, the term familial pulmonary arterial hypertension (FPAH) is to be used. In these patients pulmonary arterial hypertension $(\mathrm{PAH})$ is differentiated from pulmonary hypertension caused by left heart disease, chronic lung disease, hypoxaemia, chronic thrombotic or embolic disorders affecting the lungs and other infectious or inflammatory triggers (Table I).

This classification system is useful in that it provides evidence-based clinical practice guidelines and a rationale for treatment necessary for the approval by drug regulating authorities of new drugs for pulmonary arterial hypertension. ${ }^{(7)}$ 
Table I. WHO Classification of Pulmonary Hypertension

\begin{tabular}{|c|c|c|}
\hline I. & \multicolumn{2}{|c|}{ Pulmonary arterial hypertension (PAH) } \\
\hline & $\begin{array}{l}\text { I.I. } \\
1.2 . \\
1.3 . \\
1.3 .1 . \\
1.3 .2 \\
1.3 .3 \\
1.3 .4 \\
1.3 .5 \\
1.3 .6\end{array}$ & $\begin{array}{l}\text { Idiopathic (IPAH) } \\
\text { Familial (FPAH) } \\
\text { Associated with (APAH): } \\
\text { Collagen vascular disease } \\
\text { Congenital systemic-to-pulmonary shunts } \\
\text { Portal hypertension } \\
\text { HIV infection } \\
\text { Drugs and toxins } \\
\text { Other (thyroid disorders, glycogen storage disease, Gaucher's } \\
\text { disease, hereditary hemorrhagic telangiectasia, } \\
\text { hemoglobinopathies, myeloproliferative disorders, splenectomy) } \\
\text { Associated with significant venous or capillary involvement } \\
\text { Pulmonary veno-occlusive disease (PVOD) } \\
\text { Pulmonary capillary hemangiomatosis (PCH) } \\
\text { Persistent pulmonary hypertension of the newborn }\end{array}$ \\
\hline \multirow[t]{2}{*}{2.} & \multicolumn{2}{|c|}{ Pulmonary hypertension with left heart disease } \\
\hline & $\begin{array}{l}2.1 . \\
2.2 .\end{array}$ & $\begin{array}{l}\text { Left-sided atrial or ventricular heart disease } \\
\text { Left-sided valvular heart disease }\end{array}$ \\
\hline \multirow[t]{2}{*}{3.} & \multicolumn{2}{|c|}{ Pulmonary hypertension associated with lung diseases and/or hypoxaemia } \\
\hline & $\begin{array}{l}3.1 . \\
3.2 . \\
3.3 . \\
3.4 \\
3.5 \\
3.6\end{array}$ & $\begin{array}{l}\text { Chronic obstructive pulmonary disease } \\
\text { Interstitial lung disease } \\
\text { Sleep-disordered breathing } \\
\text { Alveolar hypoventilation disorders } \\
\text { Chronic exposure to high altitude } \\
\text { Developmental abnormalities }\end{array}$ \\
\hline \multirow[t]{2}{*}{4.} & \multicolumn{2}{|c|}{$\begin{array}{l}\text { Pulmonary hypertension due to chronic thrombotic and/or embolic } \\
\text { disease (CTEPH) }\end{array}$} \\
\hline & $\begin{array}{l}4.1 . \\
4.2 . \\
4.3 .\end{array}$ & $\begin{array}{l}\text { Thromboembolic obstruction of proximal pulmonary arteries } \\
\text { Thromboembolic obstruction of distal pulmonary arteries } \\
\text { Nonthrombotic pulmonary embolism (tumor, parasites, } \\
\text { foreign material) }\end{array}$ \\
\hline 5. & \multicolumn{2}{|c|}{ - Miscellaneous } \\
\hline & & $\begin{array}{l}\text { Sarcoidosis, histiocytosis } X \text {, lymphangiomatosis, compression of } \\
\text { pulmonary vessels (adenopathy, tumor, fibrosing mediastinitis) }\end{array}$ \\
\hline
\end{tabular}

\section{Idiopathic pulmonary arterial hypertension}

Idiopathic pulmonary arterial hypertension is pulmonary arterial hypertension of an unknown cause. The histopathological changes are angioproliferative plexiform lesions of endothelial cells, muscularization of precapillary arterioles, intimal endothelial cell proliferation, and medial thickening due to vascular smooth muscle cell proliferation. This condition is rare, more commonly found in female adults than in children, and has a poor prognosis.

Dyspnoea is the most common presenting symptom, coupled with fatigue. Later signs are cyanosis and right ventricular failure.

\section{Familial pulmonary arterial hypertension}

Genetic or familial transmission of pulmonary arterial hypertension is suspected or documented in approximately $6 \%$ to $10 \%$ of patients with pulmonary arterial hypertension. Bone Morphogenetic Protein Receptor II (BMPR2) mutations have been identified in 50\% to $90 \%$ of patients diagnosed with familial pulmonary arterial hypertension. ${ }^{(8)}$ Familial pulmonary arterial hypertension is characterized by genetic predisposition, in which members of successive generations develop pulmonary arterial hypertension, usually as adults. These patients develop more severe and rapidly progressive disease. There is, however, incomplete penetration as unaffected individuals with the BMPR2 mutations are found in these families. ${ }^{(9)}$

\section{Pulmonary arterial hypertension associated with other diseases}

At times, pulmonary arterial hypertension occurs within the course of certain other diseases frequently enough to be considered as an associated, although not necessarily clinically observed, feature of the disease. The associated disease may be appropriately regarded as one of the "hits" that leads to pulmonary arterial hypertension and can be regarded as associated with, or secondary to, pulmonary arterial hypertension.

An important member of this group in children and young adults is uncorrected congenital heart disease and systemic-to-pulmonary shunts with high pulmonary blood flow. The development of pulmonary arterial hypertension with, at times, the reversal of flow across the lesion (Eisenmenger syndrome), is most predictable when flow is high at a young age, exposing the pulmonary vasculature to systemic pressure (as with ventricular septal defect, patent ductus arteriosus, atrio-ventricular septal defect, or cyanotic congenital heart lesions with increased pulmonary flow).

Pulmonary arterial hypertension may, however, also occur with atrial septal defects, which initially have a lower pulmonary artery flow.

Connective tissue disease, especially the scleroderma spectrum, is also an important member of this group. ${ }^{(10)}$ Other conditions which also exhibit features of pulmonary arterial hypertension are portopulmonary hypertension, (II) where it has major implications for survival (50\% to $72 \%$ over 2 years), (12) exposure to certain toxic agents such as appetite suppressants derived from amphetamine, ${ }^{(13)}$ and of significance in Southern Africa, human immunodeficiency virus (HIV) infection. ${ }^{(14)}$

\section{Pulmonary arterial hypertension and left heart disease}

In significant left heart disease there is an initial passive process of back pressure, producing elevation in pulmonary venous and, secondarily, pulmonary arterial pressure. Prolonged duration of pulmonary venous hypertension may eventually lead to an adaptive increase in pulmonary arteriolar resistance. Rectifying the underlying cause, e.g. mitral valve stenosis, usually results in the pulmonary pressures returning to normal, although persistent vascular changes may persist after complete normalization of the cardiac lesion or dysfunction.

Pulmonary arterial hypertension with hypoxemia and lung diseases Hypoxia and respiratory disorders of ventilation are well recognized causes of pulmonary arterial hypertension. Pulmonary arterial hypertension is present in up to $66 \%$ of patients with stage IV chronic obstructive lung disease and is generally mild ${ }^{(15)}$ as it is in sleep-disordered breathing. When sleep-disordered breathing is coupled with hypoventilation due to severe obesity, or associated with obstructive pulmonary disease, it results in severe pulmononary hypertension. ${ }^{(16)}$ These are problems which affect children less commonly than adults.

In children, upper airway obstruction, ${ }^{(17)}$ cystic fibrosis, interstitial lung disease, developmental hypoplasia of the lungs due to bronchopulmonary dysplasia secondary to prematurity, as well as severe spinal deformities and 
neuromuscular disease are possible causes. Children have a more reactive pulmonary vasculature than adults, which is particularly susceptible to the effects of hypoxia, exercise and other stimuli with resulting pulmonary arterial hypertension. ${ }^{(18)}$

\section{Pulmonary arterial hypertension and chronic embolic disease} Chronic thromboembolic pulmonary hypertension is observed in up to $3 \%$ of patients who survive an acute embolism. ${ }^{(19)}$ It may occur in the absence of a clear history of acute pulmonary embolism. In patients with a history of pulmonary embolism, a relatively asymptomatic interval may precede presentation when more advanced arteriopathy or right ventricular failure has developed.

In children with chronic thromboembolic disease pulmonary arterial hypertension is uncommon, but may complicate sickle cell anaemia, bacterial endocarditis, a ventricular to atrial shunt for hydrocephalus and schistosomiasis. ${ }^{(20)}$

\section{PATHOPHYSIOLOGY}

The pathogenesis of pulmonary arterial hypertension is complex and not completely understood. Factors thought to be important are vasoconstriction of the pulmonary vasculature, remodelling of the pulmonary vessel wall and progressive obstruction and obliteration of the vascular bed with thrombosis. Significantly rising pulmonary vascular resistance eventually leads to right heart failure and later death. ${ }^{(21)}$

The mechanisms and structural alterations underlying these developments that lead to the progression of pulmonary vasculopathy have become increasingly better understood. Some or all of these changes may play a role in all forms of pulmonary arterial hypertension. However, some molecular and cellular substrates with their histopathologic consequences have been associated with particular types of pulmonary arterial hypertension.

The development of pulmonary vascular disease frequently originates with the interaction of a predisposing state and one or more inciting stimuli.This concept is referred to as the "multiple-hit hypothesis". (22) Two or more "hits" may consist of a genetic substrate combined with an additional genetic condition, either a mutation or polymorphism, a coexisting disease, or an environmental exposure.

Once a combination of possible initiating factors exists, various mechanisms are activated that lead to vascular constriction, cellular proliferation, and a prothrombotic state. This then results in pulmonary arterial hypertension and its clinical outcome in varying degrees, depending on the underlying and causative factors.

\section{Vasoconstriction}

Conditions resulting in hypoxaemia, especially if chronic, can lead to pulmonary vasoconstriction due to effects on the endothelium and smooth muscle cells of the arterial walls. ${ }^{(23)}$

Vasoactive mediators that affect tone and structural remodelling of the pulmonary vasculature, such as nitric oxide and endothelin-I, have been implicated in the pathophysiology of pulmonary hypertension. ${ }^{(24)}$ Reduced activity of the enzyme nitric oxide syntetase impairs the continuous supply of nitric oxide from the endothelium resulting in vasoconstriction, ${ }^{(25)}$ while the vascular effects of nitric oxide depend on its augmentation of cyclic guanosine monophosphate content in smooth muscle. Cyclic guanosine monophosphate is degraded by cyclic guanosine monophosphatediesterase, which is increased in pulmonary arterial hypertension.

Thromboxane A2, a vasoconstrictor and proplatelet aggregator and prostacyclin, a vasodilator with antiplatelet properties, are both important in regulating vasomotor tone. An imbalance between these vasoactive substances has been implicated in the pathogenesis of secondary pulmonary arterial hypertension. ${ }^{(26)}$

\section{Cellular proliferation}

Endothelial injury, dysfunction from hypoxia, inflammation or damage from haemodynamic shear stresses can cause an imbalance between a vasoconstrictive-mitogenic mediator and a vasodilator-antiproliferative mediator. This can result in an increase in vasomotor tone and vasoreactivity with smooth muscle proliferation. Thromboxane A2 and endothelin-I are vasoconstrictors and mitogens, while prostacyclin and nitric oxide are vasodilators with antiproliferative effects. ${ }^{(27)}$

\section{Prothrombosis}

Endothelial injury causes the migration of smooth muscle cells into the vascular wall, leading to medial hypertrophy and hyperplasia and, with the excessive release of locally active mediators, promotes a procoagulant state with intravascular thrombosis causing further obstruction. (27)

Eventually there is muscularisation of the pulmonary arterioles with proliferation of smooth muscle in the intima of the small pulmonary arteries, leading to intimal fibrosis and proliferation of smooth muscle in the pulmonary veins and venules. ${ }^{(29)}$

As discussed above, there are complex interactions between the different factors that contribute to the mechanisms involved.

\section{CLINICAL PRESENTATION}

Patients with pulmonary hypertension may be asymptomatic with few clinical signs, especially in the early stages of the disease. They generally present with a spectrum of symptoms and signs due to impaired oxygen 
transport and later reduced cardiac output. Where pulmonary hypertension is secondary, the causative condition may be the only initial presenting clinical abnormality.

\section{Presenting symptoms}

The most frequent presenting symptom is dyspnoea, which initially is usually exertional. ${ }^{(30)}$ As the disease progresses dyspnoea is present in virtually all patients. With further progression it may even be present at rest.

Further complaints commonly found are fatigue, weakness and exertion intolerance, depending on the age of the child. In younger children, feeding problems and failure to thrive are possible.

Since these symptoms are non-specific, the initial evaluation is often not helpful unless a related condition is recognised. Where a child presents with unexplained dyspnoea, pulmonary arterial hypertension must be considered. For example, in an infant, poor feeding with excessive sweating with puffy eyes could point to an underlying cardiac cause, while snoring and mouth breathing suggest an upper airway obstruction.

As there is a known genetic component of pulmonary hypertension, a family history could point the way, while possible HIV exposure warrants further investigation.

\section{Physical findings}

The clinical signs of pulmonary arterial hypertension are often subtle and easily overlooked, especially in young children who normally still have some right ventricle dominance during the first year of life.

Specific findings that are strongly suggestive are a palpable parasternal lift due to a hypertrophied right ventricle and an accentuated pulmonary component of the second heart sound produced by an increased pressure at closure of the valve. Other possible findings are a systolic ejection click at the left heart base and a systolic ejection murmur due to turbulent transpulmonary flow. With more advanced disease, a diastolic decrescendo murmur at the left base due to pulmonary incompetence, a pansystolic murmur of tricuspid regurgitation audible at the lower left sternal border and signs of right heart failure are possible. ${ }^{(30)}$

Cyanosis is an important sign indicative of severity. It could be due to right to left shunting at cardiac level, impaired intrapulmonary transfer or reduced cardiac output. Associated digital clubbing is seldom found in idiopathic pulmonary arterial hypertension and raises the possibility of congenital heart disease or chronic lung disease. ${ }^{(31)}$

The physical examination may provide some insight into the possible aetiology where a primary underlying cause is considered.

\section{DIAGNOSTIC EVALUATION}

\section{Chest radiography}

Chest roentgenography, although not very sensitive, may provide the first clue to the presence of pulmonary arterial hypertension. Once the disease has progressed, enlargement of the central pulmonary arteries with peripheral pruning of the pulmonary vasculature on the posteroanterior view and reduction in retrosternal air space on the lateral view due to right ventricular hypertrophy may be visible. Most patients with asymptomatic pulmonary hypertension have normal chest radiography findings. No correlation seems to exist between the extent of the radiological findings and the degree of pulmonary hypertension. ${ }^{(32)}$

The chest radiogram can also be useful in defining coexistent conditions related to or causing pulmonary arterial hypertension, such as pulmonary venous congestion or lung infiltrations in HIV disease.

\section{Electrocardiogram}

Pulmonary arterial hypertension causes right ventricular hypertrophy and later right heart dilation. The electrocardiogram (ECG) will demonstrate right-axis deviation, right ventricular hypertrophy, and anterior ST- and Twave abnormalities consistent with a right ventricular strain pattern, although it is relatively insensitive and non-specific. ${ }^{(30)}$ In severe cases with right atrial enlargement a tall P wave is seen in leads II III and aVF.

\section{Echocardiogram}

Transthoracic doppler echocardiography is an essential tool for demonstrating the presence of pulmonary arterial hypertension. When present, doppler velocity measurement of a tricuspid regurgitant signal for estimation of right ventricular systolic pressure is important. There is a high level of correlation of estimated right ventricular systolic pressure with invasively measured pulmonary artery pressure. ${ }^{(33)}$ Individual results may overestimate or underestimate actual pulmonary artery systolic pressures. When indicated, further confirmation with invasive studies is required. Echocardiography provides additional data important in the evaluation of pulmonary arterial hypertension, including assessment of right ventricular size and function.

The severity of pulmonary hypertension can also be determined using right ventricular outflow patterns and time intervals including pre-ejection period, acceleration and deceleration, relaxation and contraction times. ${ }^{(34)}$ These may be especially usefull when tricuspid and pulmonary regurgitation are not present.

Echocardiography provides left heart function analysis and morphology and can provide information indicating elevated pulmonary venous congestion as a cause of pulmonary arterial hypertension. Furthermore, 
it provides the best assessment of congenital heart disease and, in most cases, an assessment of the pulmonary artery pressure in this situation.

\section{Evaluating other risk factors for pulmonary arterial hypertension}

In patients with unexplained pulmonary hypertension, serological testing for connective tissue disease and HIV infection should be performed. Where indicated, scarcer conditions such as sickle cell anaemia, bacterial endocarditis and schistosomiasis should be excluded.

In patients old enough, pulmonary function testing is a necessary part of the initial evaluation in order to exclude, or when present, determine the contribution of any underlying airway or parenchymal disease. Oximetry and arterial blood oxygenation is part of the evaluation for the presence and severity of lung disease. ${ }^{(32)}$

Where an upper airway obstruction is considered, otolaryngeal evaluation should be performed. ${ }^{(17)}$

\section{Genetic evaluation and counselling}

Although BMPR2 mutations are clearly associated with heritable pulmonary arterial hypertension, testing poses potential difficulties. Only 10\% to 20\% of carriers of the gene mutation actually exhibit pulmonary hypertension. Testing for BMPR2 mutations is currently available at a very limited number of institutions. (35) Where there is a family history, genetic counselling is indicated.

\section{Right heart catheterisation with vasodilator testing}

Right heart catheterisation remains the gold standard by which the diagnosis of pulmonary arterial hypertension is made. It not only provides an indication of disease severity, but is diagnostic in excluding other aetiologies such as congenital heart disease, extracardiac shunts and left heart disease.

The degree to which mean pulmonary arterial pressure and pulmonary vascular resistance can be decreased acutely by the administration of fastacting, short-duration vasodilators reflects the extent to which vascular smooth muscle constriction is contributing to the hypertensive state. Because the vasodilator response has considerable therapeutic implications in idiopathic pulmonary arterial hypertension, most patients should undergo a vasodilator trial at the time of initial cardiac catheterisation. Intravenous epoprostenol, intravenous adenosine, or inhaled nitric oxide are commonly used for acute vasodilator testing. ${ }^{(36)}$

\section{Lung biopsy}

Lung biopsy is not routinely done because of the risk. Histopathological findings are often non-specific. ${ }^{(37)}$ In those circumstances where tissue examination might offer specific information, it can be considered to establish a diagnosis of conditions such as bronchiolitis or granulomatous pulmonary disease.

\section{TREATMENT}

\section{General measures}

Any underlying or associated disease that can be treated specifically takes priority over non-specific treatment. In children this is clearly of importance, as they have a longer anticipated lifespan than adults. Examples are the timely treatment of congenital heart lesions with a high pulmonary flow or the removal of lymphoid tissue causing upper airway obstruction.

Exercise and especially heavy physical activity or isotonic exercises should be avoided. Low-level aerobic exercise, such as walking, should be encouraged in older children.

Exposure to high altitudes must be avoided, because this may produce hypoxic pulmonary vasoconstriction. Patients who have to fly may require oxygen on commercial aircraft.

Because respiratory infections are particularly troublesome in these children, a full immunization program is advised, including immunisation against influenza and pneumococcal pneumonia. All respiratory infections need immediate and aggressive treatment.

Concomitant medications that include vasoconstricting sinus or cold preparations should be avoided. Certain pulmonary arterial hypertension medications have specific medication interactions, such as cyclosporine with bosentan and organic nitrates with sildenafil, and are consequently contraindicated for simultaneous use. Patients receiving warfarin anticoagulation should be counselled about the many agents that interact with this medication.

Diuretics are indicated to manage volume overload due to right ventricular failure. In some cases digoxin and intravenous diuretics are required. In these cases, serum electrolytes and renal function should be monitored.

Hypoxaemia is a potent pulmonary vasoconstrictor. Most experts recommend oxygen supplementation to maintain arterial oxygen saturation above $90 \%$.

\section{Medication}

Based on our improved knowledge of the pathogenesis of pulmonary arterial hypertension, therapy is aimed at inhibition of cell proliferation, increase of vasodilation or inhibition of vasoconstriction, inhibition of inflammatory, prothrombotic and proliferative mediators and increase of their antagonists.

The treatment of pulmonary arterial hypertension with drugs is complex and at times involves the use of sophisticated delivery systems, often intravenous, which have not been formally studied in children. Guidelines have been published for the management of pulmonary arterial hypertension in adults, and the treatment of children tends to follow a 
similar strategy although few studies have been done on children. ${ }^{(38)}$ When dealing with children, careful consideration must be given to the patients and their carers, since the benefit of intravenous treatment will depend on their ability to accept and manage drug administration, often through a central line which is not always practical, especially in younger children. Oral and other "non-parenteral" therapies are usually preferable in children.

\section{I Calcium channel blockers}

Acute vasodilator testing in the cardiac catheter laboratory should be performed to determine appropriate treatment. The definition of a positive response is a reduction of mean pulmonary arterial pressure by at least $10 \mathrm{~mm} \mathrm{Hg}$ to a value of $40 \mathrm{~mm} \mathrm{Hg}$ or less. A higher proportion of children are acute "responders" compared to adults. ${ }^{(39)}$ Patients with this response are most likely to have a beneficial hemodynamic and clinical response to treatment with calcium channel blockers. ${ }^{(40)}$ Those failing to achieve this response are unlikely to improve with calcium channel blocker therapy and their condition could worsen. (41) Children who were initially "acute responders", may become "non-responders" over time. ${ }^{(42)}$ Improved survival has been observed in both adults and children who responded to an acute vasodilator challenge and were treated with nifedipine in addition to conventional anti-failure treatment with digoxin, diuretics, and supplemental oxygen. ${ }^{(43)}$

Dihydropyridine calcium channel blockers, such as nifedipine and amlodipine that act on vascular smooth muscle are preferred. Nifedipine has a shorter half life and is preferred over amlodipine. Negative inotropic calcium channel blockers, such as verapamil, should be avoided. ${ }^{(44)}$ The optimum dose of calcium channel blockers in children with pulmonary hypertension is unknown. They should be introduced carefully and the dose titrated as tolerated.

\subsection{Anticoagulation}

Anticoagulation with warfarin has a survival benefit in adults ${ }^{(45)}$ and consequently warfarin is commonly given to children. The international normalised ratio (INR) depends on the risk of benefit and bleeding. In general, the INR range is 1.5-2. In children with chronic thromboembolic disease, the recommendation is to aim for a higher INR; while in active toddlers and children with thrombocytopenia the recommendation is an INR < 1.5. (46) In small children, the need for ongoing INR blood tests and the risk of significant bleeding can be problematic for everyone involved and warfarin is often not prescribed.

\subsection{Prostacyclins}

Prostacyclin, a metabolite of arachidonic acid is produced in vascular endothelium. It is a potent pulmonary and systemic vasodilator and has an inhibitory effect on platelet aggregation. ${ }^{(47)}$

\subsection{Epoprostenol}

When given as a continuous intravenous infusion, epoprostenol, a prostacyclin,improves exercise tolerance, symptoms, haemodynamics, and survival in children and adults. ${ }^{(48)}$ Epoprostenol decreases pulmonary vascular resistance and improves the survival in both responders and non-responders to acute testing. ${ }^{(49)}$ This raises the question of a mechanism of action other than only vasodilation. Antiproliferative and vascular remodelling effects are proposed.(50) Side effects include jaw pain, rash, diarrhoea, nausea and vomiting, light headedness, headache and flushing. The usual starting dose in children is the same as in adults, namely $2 \mathrm{ng} / \mathrm{kg} / \mathrm{min}$ with titration until the maximum tolerated dose is reached. ${ }^{(51)}$

Administration of epoprostenol requires a central venous line and a continuous infusion pump to be worn by the child. Interruption of the infusion or pump failure can result in a life-threatening hypertensive crises. Other complications are catheter-related sepsis and thrombosis.

\subsection{2 lloprost nebulised}

lloprost is a stable analogue of prostacyclin with a longer half life of 15-30 minutes compared to 2-3 minutes for epoprostenol. The duration of action for iloprost is about 60 minutes, thus frequent nebulisations are necessary. ${ }^{\left({ }^{22}\right)}$ Drug delivery direct to the lungs avoids a central intravenous catheter but needs regular inhalations, which requires compliance, often difficult in children. Side effects are similar, but more common. ${ }^{(52)}$

\subsection{Endothelin receptor antagonists}

Endothelin-I, a potent vasoconstrictor and muscle mitogen, is increased in lung tissue and plasma of patients with pulmonary arterial hypertension. ${ }^{(47)}$

\subsection{Bosentan}

Bosentan is a competitive endothelin- $A$ and endothelin- $B$ receptor antagonist. It is the only oral agent with a licence for the treatment of adult pulmonary arterial hypertension. Bonestan has been studied in 19 children aged between 3-15 years with idiopathic pulmonary arterial hypertension or pulmonary arterial hypertension related to congenital heart disease. Changes in exercise capacity and $\mathrm{WHO}$ class at 12 weeks was not significantly different from baseline conditions. The most frequent adverse effects were flushing, headache, and elevated liver enzymes. ${ }^{\left({ }^{33}\right)}$ Bosentan is being used in infants and children with severe disease. The oral dosage form is an enormous advantage in this age group. Clinical improvement has been seen in patients as young as 9 months with severe disease. ${ }^{(54)}$ 


\subsection{Phosphodiesterase inhibitors}

Phosphodiesterase inhibitors boost the effect of nitric oxide by inhibiting the breakdown of cyclic guanosine monophosphate (cGMP). In smooth muscle cells, cGMP regulates calcium influx and mediates vasodilation.

\subsection{Sildenafil}

Sildenafil is a highly specific type 5 phosphodiesterase inhibitor. It has been shown to block rebound pulmonary hypertension associated with withdrawal of inhaled nitric oxide in infants and neonates. ${ }^{(55)}$ In a small case series describing children and adults with pulmonary arterial hypertension, sildenafil is reported to improve exercise capacity, decrease pulmonary artery pressure and improve symptoms. ${ }^{(56)}$ Oral sildenafil was tolerated well, with no obvious effects on visual acuity and colour vision at a dose of $0.5 \mathrm{mg} / \mathrm{kg}$. ${ }^{(57)}$

\section{Atrial septostomy and lung transplantation}

Atrial septostomy involves the creation of a right-to-left interatrial shunt. In patients with a failing right heart and decreased cardiac output, the resulting increased left heart blood volume increases cardiac output, which, despite reduction in systemic arterial oxygen saturation, increases systemic oxygen transport. ${ }^{(58)}$ Atrial septostomy is used as a palliative measure or where advanced medical therapies are available,to buytime before lung transplantation in appropriately selected patients. Lung transplantation is generally reserved for those failing the best available medical therapy. Survival in patients with pulmonary arterial hypertension who undergo lung transplantation is $66 \%$ to $75 \%$ at I year. ${ }^{(59)}$ This procedure is only to be considered when all options have failed, and in an appropriately equipped unit.

\section{CONCLUSION}

The recent classification and better understanding of the pathophysiology with medication aimed at the underlying physiological effects has made the management of pulmonary arterial hypertension more structured.

The long-term survival of idiopathic pulmonary arterial hypertension in children has significantly improved with the advent of pulmonary vasodilator therapy. In the present era, the overall survival rate is $78 \%$ at 10 years but is still unsatisfactory. In secondary pulmonary arterial hypertension, the underlying condition usually determines the prognosis.

The use of prostacyclines in children has many problems due to the route of administration, cost, complications and availability.

Oral medication, namely calcium channel blockers, endothelium receptor antagonists and, especially, phosphodiesterase inhibitors are more promising in children when used correctly. ${ }^{(60)}$

\section{REFERENCES:}

I. D'Alonso GE, Barst RJ, Ayres SM, et al. Primary pulmonary hypertension: a national prospective study. Ann Intern Med 1991;1 15:434-49.

2. Gaine SP, Rubin LI. Primary pulmonary hypertension. Lancet 1998; 352:7| 9-25.

3. Humpl T, Janette T, Reyers, Holtby H, Stephens D, Adatia I. Beneficial Effect of Ora Sidenafil Therapy on Childhood Pulmonary Arterial Hypertension. Circulation 2005; I I 1:3274-80

4. Barst RJ, McGoon MD, Torbicki A, et al. Diagnosis and differential assessment of pulmonary arterial hypertension. J Am Coll Cardiol. 2004; 43:40S-47S

5. Rosenzweig EB, Widlitz A, Barst RJ. Pulmonary arterial hypertension in children. Pediatr Pulmonol 2004; 38:2-22

6. Simonneau G, Galiè N, Rubin L, et al. Clinical classification of pulmonary hypertension. J Am Coll Cardiol. 2004:43 (suppl I):S5-SI2.

7. Rubin LJ. Introduction: diagnosis and management of pulmonary arterial hypertension ACCP evidence-based clinical practice guidelines. Chest 2004; I 26:75-I0S.

8. Cogan JD,Vnencak-Jones CL, Phillips JA III, et al. BMPR2 gene rearrangements constitute a new cause for primary pulmonary hypertension. Genetics Med. 2005;7:169-74.

9. Deng Z, Morse JH, Slager SL, et al. Familial primary pulmonary hypertension (gene $\mathrm{PPHI}$ ) is caused by mutations in the bone morphogenetic protein receptor-ll gene. Am I Hum Genetics. 2000;67:e-pub.

10. Steen V, Medsger T. Predictors of isolated pulmonary hypertension in patients with systemic sclerosis and limited cutaneous involvement. Arthritis Rheum 2003:48:516-22.

II. Colle IO, Moreau R, Godinho E, et al. Diagnosis of portopulmonary hypertension in candidates for liver transplantation: a prospective study. Hepatology. 2003:37:40 I-9.

12. Krowka M. Portopulmonary hypertension: understanding pulmonary hypertension in the setting of liver disease. Adv Pulm Hypertens. 2004;3:4-8.

13. Abenhaim L, Moride Y, Brenot F, et al. Appetite-suppressant drugs and the risk of primary pulmonary hypertension. N Engl J Med. 1996;335:609-16.

14. Opravil M, Pechere M, Speich R, et al. HIV-associated primary pulmonary hypertension: a case control study: Swiss HIV Cohort Study. Am J Respir Crit Care Med. 1997; 155:990-5

15. Scharf SM, labal M, Keller C, Criner G, Lee S, Fessler HE. Hemodynamic characterization of patients with severe emphysema. Am J Respir Crit Care Med. 2002;1 66:3| 4-22.

16. Atwood CWJ, McCrory D, Garcia JG, Abman SH, Ahearn GS. Pulmonary artery hypertension and sleep-disordered breathing: ACCP evidence-based clinical practice guidelines. Chest. 2004; 126:72S-7

17. Grobbelaar J, Seedat RY, Brown SC, Claasen AJ. Pulmonary hypertension due to recurrent laryngeal papillomatosis: Int | of Pediatric Otorhinolaryngology 2005; 31 5-8

18. Fishman AP, Hypoxia on the pulmonary circulation, how and where it acts. Circ Res 1976:38:221.

19. Pengo V, Lensing A, Prins M, et al. Incidence of chronic thromboembolic pulmonary hypertension after pulmonary embolism. N Engl J Med. 2004;350: 2257-64.

20. De Cleva R Herman P, Pugliese $V$ et al. Prevalence of pulmonary hypertension in patients with hepatosplenic mansonic shistosomiasis-prospective study Hepatogastroenterology 2003;50:2028-30.

21. Humbert M, Sitbon $O$, Simonneau G. Treatment of pulmonary artery hypertension. N Engl J Med 2004;351:1425-36

22. Yuan JXJ, Rubin LJ. Pathogenesis of pulmonary arterial hypertension: the need for multiple hits. Circulation. 2005; 1 1 1:534-8.

23. Hirose S, Hosoda Y,Futuya S,lkeda E. Expression of endothelial growth factor correlates closely with the formation of the plexiform lesions in human pulmonary hypertension. Pathol Int 2000;50:472-9.

24. Mkhal G, Chester AH, Gibbs SR, Borland JA, Banner NR, Yacoub MH. Role of vasoactive mediators in primary and secondary hypertension. Am J Cardiol 1998:82:254-5.

25. Ginid A, Saleh D. Reduced expression of nitric oxide synthase in the lungs of patient with pulmonary hypertension. N Eng J Med 1995:333:2 I4-21.

26. Christran BW, Mcpherson CD,Newman $H$, et al. An imbalance between the excretion of thromboxane and prostacycinmetabolites in pulmonary hypertension. N Eng | Med 1992;327:70-5

27. Roy R, Couriel JM. Secondary Pulmonary Hypertension. Paed Resp Rev 2006;7:36-44.

28. Haworth SG. Pulmonary hypertension in children. Eur Respir J. 1993;6: 1037-43.

29. Heath D. Remodeling of the pulmonary vasculature in hypoxic lung disease. In: Peacock AJ (ed). Pulmonary Circulation A Handbook for Clinicians. I. London: Chapman \& Hall Medical: 1996: 17|-9.

30. Rich S, Dantzker DR, Ayres SM, et al. Primary pulmonary hypertension: a nationa prospective study. Ann Intern Med 1987;107:216-23.

31. Hclcomb BW Jr, Loyd JE, Ely EW, et al. Pulmonary veno-occlusive disease; a case series and new observations. Chest 2000; 1 18:1671-9.

32. McGoon M, Gutterman D, et al. Screening, Early Detection, and Diagnosis of Pulmonary Arterial Hypertension. Chest 2004:126:14S-34S

33. Currie PJ, Seward JB, Chan KL. Continuous wave Doppler determination of right ventricular pressure: a simultaneous Doppler-catheterization study in 127 patients. J Am Coll Cardiol. 1985;6:750-6. 
34. Chan KL, Currie PJ, Steward JB, et al. Comparison of three doppler ultrasound methods in the prediction of pulmonary artery pressure. J Am Coll Cardiol 1987:9:549-554.

35. McLaughlin VV, McGoon MD. Pulmonary Arterial Hypertension. Circulation. 2006; | |4:|4|7-|43|.

36. Barst RJ, Maislin G, Fishman AP. Vasodilator therapy for primary pulmonary hypertension in children. Circulation 1999:99:1 197-208

37. Moser KM, Bloor CM. Pulmonary vascular lesions occurring in patients with chronic major vessel thromboembolic pulmonary hypertension. Chest 1993; 103: 685-692.

38. Badesh DB, Abman SH, Ahearn GS, et al. Medical therapy for pulmonary arterial hypertension: ACCP evidence-based clinical practice guidelines. Chest 2004; 126:35S-62S.

39. Rosenzweig EB, Widlitz A, Barst RJ. Pulmonary arterial hypertension in children. Pediatr Pulmonol 2004:38:2-22.

40. Barst RJ, Maislin G, Fishman AP. Vasodilator therapy for primary pulmonary hypertension in children. Circulation 1999;99:1 197-208.

41. Archer S, Rich S. Primary pulmonary hypertension: a vascular biology and translational research "Work in progress". Circulation 2000;102:2781-91.

42. Yung D, Widlitz AC, Rosenzweig EG, et al. Outcomes in children with idiopathic pulmonary arterial hypertension. Circulation 2004; 1 10:660-5.

43. Rich S, Kaufmann E, Levy PS. The effect of high doses of calcium-channel blockers on survival in primary pulmonary hypertension. N Engl J Med 1992;327:76-81.

44. Abman SH, Ahearn GS, et al. Medical therapy for pulmonary arterial hypertension: ACCP evidence-based clinical practice guidelines. Chest 2004; 126:35S-62S

45. FusterV, Steele PM, Edwards WD, et al. Primary pulmonary hypertension: natural history and the importance of thrombosis. Circulation 1984:70:580-7.

46. Rosenzweig EB, Widlitz A, Barst RJ. Pulmonary arterial hypertension in children. Pediatr Pulmonol 2004;38:2-22.

47. Humbert M, Morrell MW, Archer SL, et al. Cellular and molecular pathobiology of pulmonary arterial hypertension. J Am Coll Cardiol 2004; 12:13S-24S.

48. Yung D, Widlitz AC, Rosenzweig EG, et al. Outcomes in children with idiopathic pulmonary arterial hypertension. Circulation 2004; I 10:660-5.

49. Barst RJ, Rubin LJ, LongWA, et al. A comparison of continuous intravenous epoprosteno (prostacyclin) with conventional therapy for primary pulmonary hypertension. The primary pulmonary hypertension study group. N Engl J Med 1996;34:296-302.

50. Kim NH, Channick RN, Rubin LJ. Successful withdrawal of long-term epoprostenol therapy for pulmonary hypertension. Chest 2003; 124:1612-5.

5।. Barst RJ, Maislin G, Fishman AP. Vasodilator therapy for primary pulmonary hypertension in children. Circulation 1999:99:1 197-208.

52. Goldsmith DR, Wagstaff AJ. Inhaled iloprost: in primary pulmonary hypertension. Drugs 2004;64:763-73.

53. Barst RJ, Ivy D, Dingemanse J, et al. Pharmacokinetics, safety and efficacy of bosentan in pediatric patients with pulmonary arterial hypertension. Clin Pharmacol Therapeutics 2003;73:372-82.

54. Vogel M, Maiya S, Haworth SG. Current experience with bosentan (Tracleer) in the treatment of pediatric patients with pulmonary arterial hypertension. Association of European Paediatric Cardiology, 38th Annual Meeting, Amsterdam, 28-31 May 2003 Abstract 195.

55. Atz AM, Wessel DL. Sildenafil ameliorates effects of inhaled nitric oxide withdrawal. Anesthesiology 1999;91:307-10

56. Abrams D, Schulze-Neick I, Magee AG. Sildenafil as a selective pulmonary vasodilator in childhood primary pulmonary hypertension. Heart 2000;84:E4

57. Tilman H, Janette T, Reyes RN, Holtby H, Stephens D, Adatia I. Beneficial Effect of Ora Sildenafil Therapy on Childhood Pulmonary Arterial Hypertension. Circulation. 2005; I I 1:3274-3280

58. Sandoval J. Gaspar J. Pulido T, et al. Graded balloon dilation atrial septostomy in severe primary pulmonary hypertension. J Am Coll Cardiol. 1998; 32:297-304.

59. Mendeloff EN, Meyers BF, Sundt TM, et al. Lung transplantation for pulmonary vascular disease. Ann Thorac Surg. 2002;73:209-17.

60. Yung D,Widlitz AC, Rosenzweig EB, Kerstein D, Maislin G, Barst RJ. Outcomes in Children With Idiopathic Pulmonary Arterial Hypertension. Circulation. 2004; I 1 0:660-5 